JOURNAL OF APPLIED CRYSTALLOGRAPHY

ISSN 1600-5767

Keywords: book reviews.

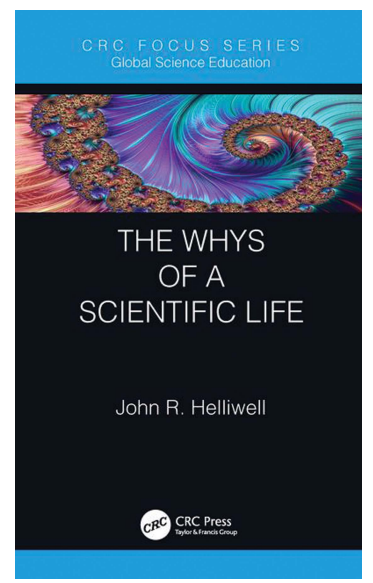

(C) 2019 International Union of Crystallography

\section{The Whys of a Scientific Life. By John R. Helliwell. CRC Press, 2018. Pp. 120. Price (hardback) GBP 43.20. ISBN 9781138389793.}

\author{
Andreas Roodt* \\ University of the Free State, Bloemfontein 9300, South Africa. *Correspondence e-mail: roodta@ufs.ac.za
}

An urban legend making its way around our university some years ago described a lecturer in philosophy who gave the students in class a one-question test - 'Why?' - and demanded an appropriate answer. Legend has it that many students with four-page answers barely passed the test, while the student claiming full marks had two words written on his script: 'Why not?' I guess the true answer lies somewhere between a four pager and two words, since some (obvious) answers in science require less motivation than others, depending on the target audience. This closely relates to the (still) debated approach of 'reductionism versus holism/expansionism' (Fang, \& Casadevall, 2011; Mensah et al., 2018) in science. The latter, when ordered in a systematic way, constitutes the cornerstone of IIASA (International Institute for Applied Systems Analysis, Laxenburg, Vienna, Austria).

This book by J. R. Helliwell finds an appropriate midway between being too elaborate and too brief, and succeeds in my opinion very well in bringing a balance of important aspects associated with a 'scientific life'. It is easy to read and contains well thoughtthrough content.

Since it explores many aspects important to a scientific life, two side comments on scientific research and what it encompasses from variable viewpoints are appropriate:

(1) A few years ago, I was reprimanded by a colleague from a classic humanities faculty on campus regarding an earlier comment which I made about the definition of 'scientific research'. It was underlined to me that the research done in humanities is clearly also 'scientific'.

(2) My son, whose passion lies in humanities, further pointed out in a discussion that in natural science there is usually just one correct answer, based on firm natural scientific principles. However, in many a non-natural-scientific domain there is often/mostly more than one equally acceptable - and correct - answer.

Be that as it may, the questions associated with 'science' as broadly defined in this book always come to the fore in every emerging scholar's life, whether in the classic hard or soft sciences. The increasing interdisciplinarity within projects, clearly more prevalent globally, also renders the 'Whys' and the 'Becauses' as presented relevant to all scholars. It is manifested in those typical 'Why?' questions many an undergraduate or postgraduate student across the sciences has posed to his/her supervisor/mentors, starting with basic project identification, different sub-divisions within a project, future prospects, applicability of the project, and so forth.

Most likely many readers of this book will have been confronted with these questions, and providing appropriate answers is not always that easy.

In my view the author goes a long way to doing exactly that in a very appropriate manner and relates issues directly relevant to a 'true' scientific (research) life. He also includes necessary and even some unmissable and philosophical approaches to move forward.

The book starts from 'Why' and then provides answers under 'Because' in 23 concise and easily readable short chapters.

After the introductory chapter follow seven sections under headings Fundamental Science, The Role of Technology, The Wider Research and Work Environment, The Scientist's Inner Self, Communication of Science, Science and Society and Fundamentals Revisited. Each of these sections covers concise points which are further elaborated in 
sub-section chapters to address selected points and attempt to provide (some) answers thereto.

Under the first four sections (Fundamental Science to The Scientist's Inner Self) are presented some 15 answers under headings Because...., followed by two questions under Communication of Science, and another two 'Because' answers and an examination of the Importance of the 'Whys of a Scientific Life' related to Science and Society. Two final questions under Fundamentals Revisited are presented in Chapters 22 and 23. The book concludes with a brief Appendix, followed by the usual alphabetical keyword Index.

Many readers can probably add more and different subheadings of specific interest to their experiences and environment, and challenges which make the choices within a scientific life somewhat harder. In particular, those more isolated young scientists in remote locations and in more underdeveloped countries, compared with students at the world's best, well equipped and well known universities/ research laboratories, will surely have different perspectives and importance attached to many of the points made. Maybe the title could have omitted 'The' and only been Whys of a Scientific Life, since as is it implies all the 'Whys' have been covered.

Nevertheless, since these many points are indeed made, it provides stepping-stone arguments to be further considered and explored. Apart from providing the reader with concise answers to the questions posed, it is also well illustrated by many appropriate and seminal examples from the literature, fitting to the stepwise points made.

Thus, to readers who are passionate about their research, this book provides a very appropriate perspective and a systematic approach to many relevant questions, directly related to the conscious choice of pursuing a scientific life. It was a pleasure to read and provides clear answers to many a 'Why' associated with scientific research across disciplines.

The author in my view provides a well thought-through 'rough guide' to be considered by many a scientist. It should be shared with colleagues, students, and even people in the street, general society, management entities, and decision makers of higher academic institutions and in government: specifically, with those who so often query with variable modes and emphasis 'Why is scientific research (really) necessary?'

\section{References}

Fang, F. C. \& Casadevall, A. (2011). Infect. Immun. 79, 1401-1404. Mensah, P., Katerere, D., Hachigonta, S. \& Roodt, A. (2018). Editors. Systems Analysis Approach for Complex Global Challenges. Heidelberg: Springer. 